\title{
EXPLORING COMPLEX SOCIOCULTURAL SITUATIONS THROUGH SOFT OPERATIONAL RESEARCH
}

\author{
Maurice Yolles \\ Centre for the Creation of Coherent Change and \\ Knowledge (C4K) \\ Liverpool John Moores University (LJMU) \\ Liverpool L3 5UX, United Kingdom \\ prof.m.yolles@gmail.com
}

Recebido em 04/2009; aceito em 03/2010 após 1 revisão

Received April 2009; accepted March 2010 after one revision

\begin{abstract}
A paradigm can be thought of as a living commodity system, carried by a self-organising group. The commodity is often "practical knowledge", and the paradigm maintains a life cycle that begins with commodity gestation, leading to commodity depreciation through death or transformation. During its normal life processes paradigm grow their commodities incrementally, but the growth processes become bounded through the very conceptualisations that made them successful, limiting their pragmatic capabilities. Paradigms have not only normal lives, but also post-normal lives. In the current cultural environment normal paradigmatic life processes are said to be hard, while post-normal ones are said to be soft, with this change being facilitated through epistemological shift. An illustration of a new framework called sociohistory is shown to be a soft OR approach. Its purpose is to describe, explore and evaluate complex sociocultural problem situations, with the potential to create intervention strategies that might be able to improve them.
\end{abstract}

Keywords: Operational Research; paradigms; commodity systems; normal science; post-normal science; uncertainty; soft operational research; sociocultural problem situations; intervention strategies. 


\section{Introduction}

This paper should be seen as an extension of Yolles (1998) which discusses the nature of the Soft OR (SOR) paradigm and how it came into being. Fundamentally, SOR is concerned with complex, messy and unclear situations in which there are few universals, and where perspectives in any social environment is relativistic and pluralistic though the multiplicity of people who compose the social. Rosenhead (1989) has argued that in particular SOR has been concerned with complex problem situations, where three characteristics of complexity are that:

(a) situations are more complex when they involve people;

(b) complex situations may not be well-structured, in particular because cause-effect relationships may not be determinable;

(c) complexity is enhanced when situations are uncertain.

Hence, typically SOR are concerned with situations that:

1. Are non-optimising, looking for alternative solutions acceptable on separate dimensions, without trade-offs.

2. Have reduced data demands, achieved by greater integration of hard and soft data with social judgements.

3. Support simplicity and transparency, aimed at clarifying the terms of conflict.

4. Conceptualise people as active subjects.

5. Facilitating planning from bottom up.

6. Accepts uncertainty, and aims to keep options open for later resolution.

Yolles (1998) has also shown that the shift to embrace SOR from its traditional hard position could actually be quantitatively tracked across the decades since the 1940s (Figure 1).

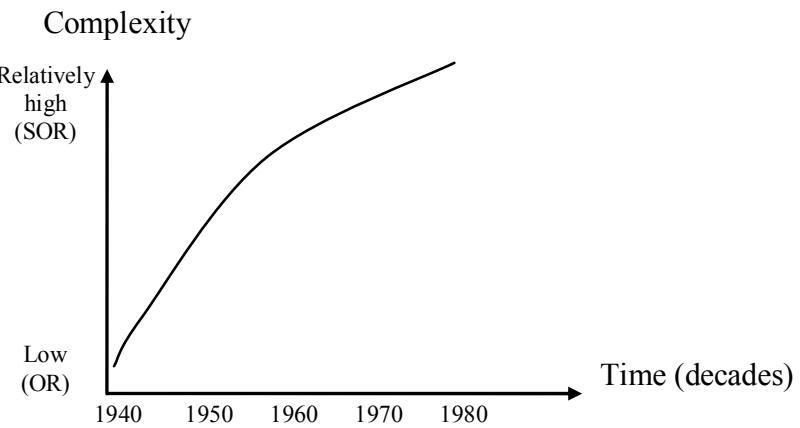

Figure 1 - Aggregate Tendency of OR Paradigm Development to Deal with Complexity. (adapted from Yolles, 1998)

In this paper the intention is to develop on this work, in two ways.

Firstly it will argue that the OR community maintains distinct sub-groups that exist as social "living systems". They maintain cultural, ideological and practical positions that are expressed through the surrogate paradigms that they hold. From this axiom, it is possible to 
use the meta-theory of Knowledge Cybernetics to show that OR paradigm change can be represented through a life cycle. The life cycle highlights 4 modes of paradigmatic existence. In "normal" mode 1 OR paradigms tend to seek homeostatic processes of development in which equilibrium is dynamically maintained. In "post normal" mode 2 they develop through bounded instability as they struggle to respond to the complex environments that they perceive to be around them. In mode 3 of crisis, paradigms may change either by regaining their homeostatic positions, changing the way in which they operate, or demising.

Secondly, we shall provide some exposure to an embryonic SOR that explores complex socio-cultural environments. The approach uses soft aspects of the Knowledge Cybernetics (KC) meta-theory to set up a model of a general complex socio-cultural environment, and then adopts its formal mechanisms that have a potential to create an OR measuring instrument. KC has integrated Roy Frieden's (1998) quantum theory called Extreme Physical Information (EPI), which transforms it from a qualitative soft approach to one that has the capacity to embrace OR interests in creating measuring instruments that are capable of formally responding to and resolving specific inquiries. This satisfies both the requirements in SOR of "reduced data demands, achieved by greater integration of hard and soft data with social judgments." It also enables the creation of an OR framework that is able to explore complex problem situations, that is data directed, and that provides the capacity for developing intervention strategies that respond to specific improvement needs identified with problem situations. The framework that is developed for this synergy is the complex domain of socio-cultural dynamics. As a SOR framework, it needs to conform to the characteristics that represent a SOR approach. Called Sociohistory, this framework has not yet been adequately developed for quantitative exploration because of time and manpower limitations, but there is a great potential for this to develop. This synergistic meta-framework of $\mathrm{KC} / \mathrm{EPI}$ has also been embryonically directed towards another complex area, that of personality theory (Yolles, 2007, 2009).

\section{The Paradigmatic Life Cycle}

\subsection{Shifts in the OR Paradigm}

We take paradigms as living commodity systems that exist by virtue of the dynamic selforganising social groups that carry them. Our interest in this paper lies with the specific paradigms that adopt a single type of thematic commodity that arise through a definable theoretic doctrine held by its carriers. They normally change incrementally over time, but this is only part of their life cycle that is constituted through commodity gestation, birth, growth, development, maturity and death/transformation. Gestation involves the formation of an ideology that during birth becomes doctrinal as it forms a body of instruction about the specific set of beliefs assembled that explains reality, and prescribes goals for phenomenal behaviour. Where a paradigm survives at least through to the development stage they may be considered as durable. They endure because of the group cultures of the social groups that carry, maintain and gradually extend them.

Paradigms have existed as long as groups have been able to form, create a collective culture, and behave normatively. This behaviour is constituted through phenomenal knowledge. Since the $17^{\text {th }}$ Century as applied science has developed, the phenomenal knowledge may be thought of as practical knowledge or "know-how", with paradigmatic growth facilitated by its potential economic value. This has gradually become connected with a growing sensate

Pesquisa Operacional, v.30, n.2, p.345-370, Maio a Agosto de 2010 
tendency to be measured and acquired through the materialist value of money as opposed to the ideational tendency of good. Economic value is today demonstrated in the scientific community when research grants are offered for the development of scientific paradigms, or when their commodities are sold through consultancy. In commercial paradigms economic value is demonstrated through the products or service that are produced through the practical knowledge that is held by the members of the group, and applied through their behaviour. The normal processes of paradigmatic development is that it grows its commodity incrementally; in modern times this occurs as it moves from old problems to new problems through conjectures, their practical assessments, their validations, and their implementations. However, like the blank page that slowly becomes filled with a single thematic configuration, the capacity of a paradigm is informed by a given epistemologically that become doctrinally bounded.

We are used to normal processes of paradigmatic developed and incremental growth. However, paradigms may become culturally unstable and bifurcate allowing two sets of values to appear, each connected with a distinct subgroup, exposing the group as a whole to the potential of cultural conflict that can lead to both direct and collateral damage in the development of a paradigm. Historically this happened in physics when the Newtonian understanding of the nature of light was bifurcated into two theories: the wave and corpuscular theories (Hoffman, 1947).

There are boundaries on the continual incremental growth of paradigmatic commodities. This has been shown in the case of the Club of Rome Limits to Growth report (Weizsäcker et al., 1997). One explanation for such boundedness is provided by Wilson (1984) who, in creating his argument, has the work of Carl Jung in mind:

"When the imperatives of various life stages are not attended to, i.e., when particular calls for use of different kinds of energy are ignored and the person continues to rely only on those functions and attitudes one can readily "handle," the commitment to growth stops and the drive to employ those new untapped energies is dammed up. If continued long enough, this can produce those dramatic mid-life upheavals we all know about: the disciplined, sensate Wall Street broker suddenly flips and is off to join the flower children in their grooving intuitive commune, etc. Jung had a wonderful Greek word for this phenomenon: enantiodromia, which says literally that "things run into their opposites" and actually means that if any of the energies that belong to the fullness of the humanum is blocked and has no acceptable outlet for any extended period of time, it will turn back on its host like a mighty tidal wave engulfing all that seemed to have been built so solidly. Such is the stuff of dramatic religious conversions - as well as the collapse of self in narcissistic anarchy. It is interesting that this is one concept that Jung did apply beyond the level of the individual self and its journey, but characteristically he applied it, not to the middle level of organizations and institutions, but rather to the macro-level of great world cultures and civilizations which skew the revelation of the humanum in one direction for centuries until the pendulum finally swings back with a vengeance.

Wilson is referring here to the dramatic shifts that affect a living system when it is unable to maintain its normal process, and this typifies all form of living system, including social ones and through this the paradigms that they carry.

It has been suggested that the normal incremental commodity growth process of a paradigm may be implicitly bounded through the limitations of its epistemological resources. New 
epistemologies may arise that challenge it, and these may drive dramatic changes and the sudden appearance of new species of paradigm. Yolles (1998) explored this situation for Operational Research (OR) with the development of two shifts in epistemology, and this paper may be seen as an extension of that 1998 study. OR, like any other disciplines, operates through its paradigms with their value ${ }^{1}$-rich and knowledge-rich (propositional) cognitive base that exists in a metasystem, their information rich figurative or theoretical/logical base that exists in its virtual system, and a data rich pragmatic base (constituted by its normative modes of practice that respond to standards of validity that constitute evidence) that exists in its system, and is orientated towards both measurement and intervention (Yolles, 2006). Yolles argues that paradigms, through the groups that carry them, have a capacity to change, but they may be bounded by the very conceptualisations that at one time made them successful. The idea of complexity facilitates explanations about phenomena that traditional paradigms are unable to explain. The 1998 paper by Yolles attempted to characterise the degree of complexity of a paradigmatic view in terms of structure, hardness, and uncertainty, and illustrate that OR paradigms follow a direct pathway from simplicity to complexity when measured against these variables.

Rosenhead (1989) identified the distinctions between hard and soft paradigms in OR, and argued that it has embraced an epistemological shift. It now maintains three epistemologies that create hard, transitional, and soft perspectives. Hard perspectives are related to the possible way the elements of a situation can be seen. Tangible things dominate which are definite and examinable. Their properties can be objectively defined and measured or assessed in some way that does not depend on personal values. In contrast, soft perspectives see situations as being composed of soft entities which are relative to people and their mental perspective. They have properties that cannot be measured objectively. Personal values, opinions, tastes, ethical views, emotions, or weltanschauung are examples. People and their psychological needs dominate. Softness is therefore directly related to subjective mentality. The shift from hard to soft was occurred through a transitional position that a number of OR paradigm holders adopted, as a way of addressing some of the inadequacies of the hard approach to explore more complex situations. These distinctions, adapted from Yolles (1998), are shown in Table 1.

The interest in SOR is consistent with the increasing importance of complexity paradigms. There are a number of meta-frameworks that embrace this, which for Oakley (2004) provides the capability of reflecting "a theory of meaning" through its meta-theory so that it can respond to both theory-doctrine and problem based issues. Constraining meta-frameworks with context creates frameworks that can explore given types of complex situation, and if they are to satisfy the needs of OR, they must be able to embrace both qualitative and quantitative attributes. Examples of such meta-framework approaches are Nicolis \& Prigogine's (1989) Complexity Theory, Beer's (1985) Managerial Cybernetics, and Yolles's (2006) Knowledge Cybernetics (KC). The first of these is well known to have been formulated into frameworks that have both qualitative and quantitative formulations (see Lucas, 2002). 
Table 1 - Three Epistemological Positions for OR.

\begin{tabular}{|c|c|c|}
\hline Hard & Transitional & Soft \\
\hline $\begin{array}{l}\text { Embrace certainty and } \\
\text { determinism }\end{array}$ & $\begin{array}{l}\text { Attempts made to abolish future } \\
\text { uncertainty. }\end{array}$ & $\begin{array}{l}\text { Embraces uncertainty and seeks } \\
\text { options for later resolution. }\end{array}$ \\
\hline Identify objectives with weights & $\begin{array}{l}\text { Problem formulation occurs in } \\
\text { terms of a single objective that } \\
\text { is optimisable, but there may be } \\
\text { multiple objectives that may be } \\
\text { traded off one against the other } \\
\text { on some form of common scale. }\end{array}$ & $\begin{array}{l}\text { Non-optimising, looking for } \\
\text { alternative intervention } \\
\text { strategies that might constitute } \\
\text { solutions/ resolutions } \\
\text { acceptable in separate } \\
\text { dimensions, without trade-offs. }\end{array}$ \\
\hline $\begin{array}{l}\text { Identify alternative courses of } \\
\text { action }\end{array}$ & $\begin{array}{l}\text { There are overwhelming data } \\
\text { demands, with accompanying } \\
\text { problems of data (including } \\
\text { distortion, availability, and } \\
\text { credibility), and where } \\
\text { consensus is assumed possible, } \\
\text { with the approach adopted } \\
\text { assuming depoliticisation, and } \\
\text { scientificisation. }\end{array}$ & $\begin{array}{l}\text { Reduced data demands, } \\
\text { achieved by greater integration } \\
\text { of hard and soft data with social } \\
\text { judgments. }\end{array}$ \\
\hline $\begin{array}{l}\text { Predict consequences of actions } \\
\text { in terms of objectives, usually } \\
\text { as a cause-effect relationship }\end{array}$ & $\begin{array}{l}\text { People are treated as passive } \\
\text { rather than active participants in } \\
\text { the situation. }\end{array}$ & $\begin{array}{l}\text { Simplicity and transparency, } \\
\text { aimed at clarifying the terms of } \\
\text { conflict. }\end{array}$ \\
\hline $\begin{array}{l}\text { Evaluate the consequences on a } \\
\text { common scale of value }\end{array}$ & $\begin{array}{l}\text { Assumption of a single decision } \\
\text { maker with abstract objectives } \\
\text { from which concrete actions } \\
\text { can be deduced for } \\
\text { implementation through a } \\
\text { hierarchical chain of command. }\end{array}$ & $\begin{array}{l}\text { Conceptualises people as active } \\
\text { subjects. }\end{array}$ \\
\hline $\begin{array}{l}\text { Select the alternative whose net } \\
\text { benefit is highest, that is the } \\
\text { optimal solution. }\end{array}$ & $\begin{array}{l}\text { Seeks to pre-take future } \\
\text { decisions. }\end{array}$ & $\begin{array}{l}\text { Facilitates planning from } \\
\text { bottom up. }\end{array}$ \\
\hline
\end{tabular}

\subsection{Paradigm Change}

It is possible to create a model of how paradigms develop and change. According to Kuhn paradigms involve four dimensions of common thought: common symbolic generalizations; shared commitment to belief in particular models or views; shared values; shared commitments of exemplars (concrete problem interventions), and is constituted as 'the set of views that the members of a...community share" (Kuhn, 1970, p.176). For Yolles (1999) paradigms operate through a metasystem (that maintains a group culture and that formulates its belief system and accumulates knowledge), a virtual system (within which operates it rationality and where it accrues information), and a system (that enables data rich structured modes of practice to develop).

Science has been having problems with normal paradigms. This can be inferred by a principle of proportional interest that the academic community has in ideas about paradigmatic change. The boundary publication for such change, proposing that paradigms change from a "normal" condition to a "revolutionary" one, after the development of a 
"crisis", came from Kuhn (1962, 1970). If one assumes that interest in such ideas are concentrated by the development of circumstances that demand reflection on them, then interest in Kuhn's ideas on paradigmatic change would be expressed through academic literature citations of his 1962/1970 book The Structure of Scientific Revolutions (with first edition in 1962, and second edition in 1970). Citation indexes provide a means for exploring this, and one easily accessible citation index generator is the Harzing "publish or perish" instrument, which uses Google Scholar as a citation source. For our purposes it has two useful indices: the $h$-index is the level of impact of research output, and the $g$-index is the level of impact - normalised for more highly cited publications. It is possible to seek citations for Kuhn's publication The Structure of Scientific Revolutions by using the title as a phrase through which to search science publications. The results extraordinarily point to around 156,000 citations, with values of $\mathrm{h}=172$ and $\mathrm{g}=365$. The large number of citations and the high value for the $g$-index impact is an illustration of the significance of Kuhn's ideas on paradigm change at this time, from which one may indeed infer that that academics are seeking explanations for the inadequate performance of their traditional paradigms.

We have indicated that the paradigmatic development process proposed by Kuhn (1970) supports the notion that scientific paradigms pass from normal mode through crisis to revolution. Normal science paradigms are realist in nature (Rauterberg, 2000), and have their history in the ideas of Descartes who believed that foundational concepts are known intuitively through reason, and that truths can be deduced with absolute certainty from our innate ideas. In essence the development of normal science paradigms embrace processes of continuous change in theory when the implications of its logical base pass through a morphogenesis that follows on the heels of a shift in cultural values. They operate in a thematic application domain that supports a dominant epistemology that allows for only a unitary perspective for the construction of knowledge. They also assume certainty, and the possibility of making predications. Normal science paradigms refer to the routine work in which knowledge is gradually accumulated in accord with established theoretical assumptions. For Kuhn it involves puzzle-solving, through which it becomes enlarged as its frontiers of knowledge and techniques are pushed forward. In particular, normal science paradigms operate as homeostatic systems that seek to be deterministic and hence certain in their patterns of knowledge. Over time paradigms change deterministically and reversibly (Prigogine \& Stengers, 1984). Processes of change involving randomness or irreversibility are exceptional.

For Kuhn, crisis is also important providing a boundary for entry into paradigmatic revolution. It can be argued to arise at the dissipative ${ }^{3}$ edge of the dynamic group that carries the paradigm, and since the groups operates through a culture, competing cultural values appear as uncertainty and relativism becomes established. As such, the role of paradigms is attenuated through human carrier estrangement from them. As the crisis deepens, paradigm carriers commit themselves to some concrete proposal for reconstruction to a new framework. Where different frameworks exist, communication fails and loses its semantic content as polarization develops, when members of the different camps become constrained by the boundaries of their paradigm (Hatch \& Cunliffe, 2006). For Fischer (1992) crisis corresponds to an unstable cognitive strategy that oscillates between the constraint of normal science and a search for a better frame of thought - one that might allow a novel integration of fragmentary representational structure that exist across a plurality of paradigms on a higher level of abstraction, differentiation, and integration. It is here that the social forces of unity, consensus, and commitment become more fluid, and new social ties, circles, and networks form, while new virtual paradigms ${ }^{4}$ may rise or fall. 
Revolutionary science arises, for Kuhn, as a metaphor for paradigm change that comes from political struggle. In particular, however, it refers to a transformative mode of change for paradigms that come together with dramatic shifts in thought through the harnessing of new epistemologies. The transformative period results in confusion within a framework of presuppositions about what constitutes a problem, a solution, and a method, and where the rationality of issues is replaced by emotionality. They are settled not by logic, syllogism, and appeals to reason, but by irrational factors like group affiliation and majority or 'mob rule' (Casti, 1989, p.40).

The three modes of paradigm change can be elaborated into four through the notion of Ravetz (1999) and Funtowicz \& Ravetz (1993), who talk of post-normal science. This is indicative of a condition where situational facts are uncertain, values in dispute, stakes high and decisions urgent. Hessels \& van Lente (2008) in their discussion of post-normal science recognize that it refers to the limitations of rational decision-making, and engages with value plurality and public participation in attempts to facilitate outcomes to complex public policy decision. In a broader sense than that posited by Ravetz, post-normal science engages with uncertainty for complex situations in which there exist plural relativist political processes. Since post-normal science paradigms embrace uncertainty in relation to their inputs, the paradigm embraces a far-from-equilibrium state (Prigogine \& Stengers, 1984) which requires work to maintain stability. Here, the paradigm's cognitive base propositional structure the principles that arise from them become dissipative and subject to fluctuation, and it is unable to provide a stable narrative that adequately explains its environment and the lack of semantic applicability of its outputs.

It is clear from all of this that paradigms are dynamic, and if they are able to maintain their existence through their group of carriers, then they can be classed as being durable and viable. The viability life span of a paradigm can be tracked according to the theoretical work of Eric Schwarz (1997), which explains in detail the characteristics that would be expected in the dynamic shifts in the paradigm.

\subsection{The Change Dynamics of Viable Paradigms}

According to Yolles (1999) systems survive dynamically through maintaining stability. How they do this becomes the centre of discussion of viability. Much of the theory today relates directly to the mathematics of dynamic systems that has previously been applied to the natural sciences. It has also been applied to human behaviour (for instance in the 1960's through differential game theory as developed by Isaacs), but this has been unable to characterise the complexities of situations involving purposeful behaviour. Theory has developed through complex general systems that explain the way in systems respond to change, and it involves mathematical bifurcation theory. This describes topological change that occurs as system discontinuities. Topology relates to graphical form. By this we mean the discontinuities that can be described in the form and related behaviour of the systems that we are observing when it changes spontaneously. If a system bifurcates, it can change in one or more possible ways, referred to as bifurcation branches.

Consistent with this, and other prominent ideas in far-from-equilibrium systems, Schwarz $(1997,2001,2003)$ has developed a model that describes the possible dynamics of a system under change, and this model can easily be applied to a paradigm that exists as a "living systems" (Beer, 1980) through the dynamic social group of paradigm carriers. 
An adaptation of this model is presented in Figure 2, and explained within the context of Yolles (1999). It shows how paradigms that exists in the homeostatic change of "normal life" may change incrementally; but they can shift into a far-from-equilibrium condition as tropic drift is engaged, and this epitomises its "post-normal life". With the increase in fluctuation that often accompanies extreme degrees of uncertainty, the next phase is ALEA when the "paradigmatic life" of crisis is reached, and where bifurcations become possible. Three options are open to paradigms that pass through bifurcation. Either the paradigm becomes disorganised and effectively (or actually) dies; or it survives its period of uncertainty and is recycled; or finally it shifts its "paradigmatic life" to the transformational phase of metamorphosis, where cognitive values change, dramatic morphogenesis leads on to very new forms of practice and a change in the way measurements are taken ${ }^{5}$. The terms of Figure 2 are defined in Table 2.

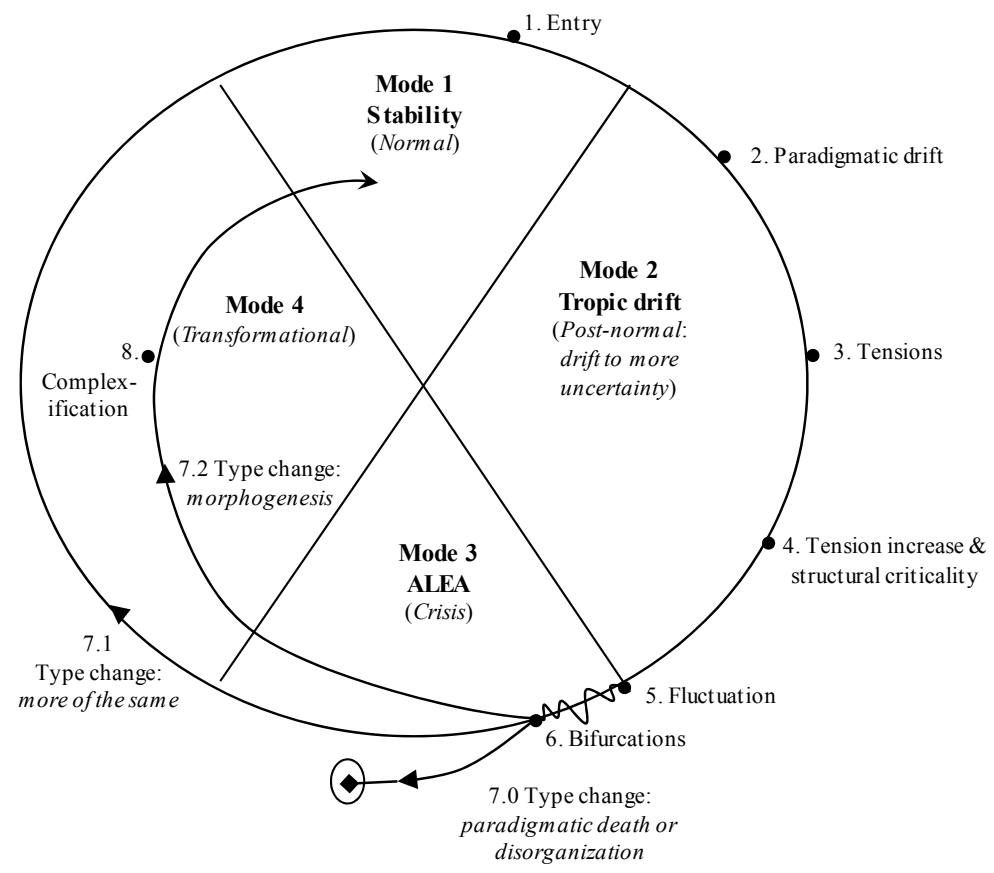

Figure 2 - Dynamics of Viable Systems (adapted from Schwarz, 1997).

Returning to the theme of this paper, the shift from hard OR that operates in relatively simple environments, to SOR that operate in complex environments and involves uncertainty, is supportive of new inquiry approaches that that are represented by features described in Table 1.

In the next section it is our intention to describe a recently developed meta-framework approach that has the potential to operate as an OR framework, operating in uncertain postnormal environments. Called Knowledge Cybernetics, the framework that it is used to create arises in Yolles et al. (2008). 
Table 2 - Explanation of the options for paradigmatic change.

\begin{tabular}{|c|c|c|c|}
\hline \multicolumn{2}{|c|}{ Paradigm } & \multirow{2}{*}{ Step } & \multirow{2}{*}{ Movement towards evolution } \\
\hline Mode & Phase & & \\
\hline Normal & \begin{tabular}{|l} 
Stable \\
(homeos- \\
tasis)
\end{tabular} & 1. Entry & $\begin{array}{l}\text { Existing durable systems are dynamically stable structures, } \\
\text { with homeostatic negative feedback loops that dominate. } \\
\text { The paradigm exists with a stable belief system and } \\
\text { rationality, though during normal development the base } \\
\text { may change its form gradually through morphogenesis. }\end{array}$ \\
\hline Post-normal & Tropic drift & $\begin{array}{l}\text { 2. } \text { Paradigmatic } \\
\text { drift } \\
3 \text { Tension } \\
\text { development } \\
4 \text { Tension increase } \\
\text { and structural } \\
\text { criticality }\end{array}$ & $\begin{array}{l}\text { Tropic drift involves actualization of the potentialities of } \\
\text { the system. } \\
\text { Dissipative processes are introduced as the paradigm and } \\
\text { its rationality is seen as being incapable of delivering its } \\
\text { logical promises. In a complex application domain, tropic } \\
\text { drift enables unexpressed potentials to be actualized. The } \\
\text { drift takes the paradigm away from its stable position and } \\
\text { gives rise to tensions between its ability to explain and } \\
\text { predict, and questions about its methods in relation to } \\
\text { observations. }\end{array}$ \\
\hline Crisis & ALEA & $\begin{array}{l}\text { 5. Fluctuations } \\
\text { 6. Bifurcations } \\
\text { 7.0 Paradigmatic } \\
\text { demise }\end{array}$ & $\begin{array}{l}\text { ALEA refers to crisis, randomness, and hazard. Here } \\
\text { positive feedback can be triggered. Tensions, following the } \\
\text { tropic drift that moved the paradigm away from its stable } \\
\text { normal mode life, lead it to structural criticality where work } \\
\text { is required by the paradigm holders to maintain its stability. } \\
\text { If the paradigm loses robustness, fluctuations are amplified. } \\
\text { Fluctuations occur internally, or in the environment as } \\
\text { noise. Through amplification of fluctuations due to tensions } \\
\text { following uncertainty drift, a discontinuity occurs in the } \\
\text { causal sequence of events/behaviour. } \\
\text { When bifurcations occur the paradigm is able to take a } \\
\text { variety of possible paths in its pragmatic behaviours. At } \\
\text { this point three options are possible. } \\
\text { In type } 7.0 \text {, decay represents a process of disorganization, } \\
\text { regression, or extinction of the paradigm, ultimately } \\
\text { leading to the possible loss of group member carriers. This } \\
\text { can be seen as the start of a catastrophe bifurcation. } \\
\text { In type } 7.1 \text { the process of change begins with "more of the } \\
\text { same" small changes that maintain its current state but do } \\
\text { not resolve issues. }\end{array}$ \\
\hline $\begin{array}{l}\text { Trans- } \\
\text { formation }\end{array}$ & $\begin{array}{l}\text { Meta- } \\
\text { morphosis }\end{array}$ & $\begin{array}{l}\text { 7.2 Type } 2 \text { change } \\
\text { 8. Complexification }\end{array}$ & $\begin{array}{l}\text { Metamorphosis involves a cascade of mutually provoked } \\
\text { events through self-organization mainly through positive } \\
\text { feedback. } \\
\text { In type } 2 \text { change, metamorphosis occurs through } \\
\text { emergence that begins in the logical base of paradigm, and } \\
\text { is amplified within its critical structure leading to a new } \\
\text { rationality that drives new propositions and consequently } \\
\text { new forms of practice. This is referred to as morphogenic } \\
\text { change, occurring through amplification and } \\
\text { differentiation. It is a relational process that develops in the } \\
\text { paradigm through positive and negative feedback, and } \\
\text { integration, when and the new cognitive base is manifested } \\
\text { figuratively and pragmatically. } \\
\text { This is accompanied by processes of complexification that } \\
\text { can occur during iteration of the spiral, perhaps leading to } \\
\text { paradigmatic autonomy. }\end{array}$ \\
\hline
\end{tabular}




\section{An Embrionic SOR Paradigm}

\subsection{Sociocultural Inquiry}

One of the more difficult areas of inquiry is the human sociocultural systems because of highly complex nature and our lack of understanding the local rationalities and purposes. So for instance, why has Islamic terrorism arisen, what is the sociocultural basis for the differences with Western socioculture that result in terroristic behaviour, and is it possible to identify any intervention strategies that can resolve the issue? By resolution, we disregard approaches like the imposition of security measures that are despotic in nature and against the interests of harmony and sociocultural health. Within the OR context, this then leads to other research questions such as, what measurable are there, how can the measures be made, and how can they be used to create and evaluate the possible set of intervention strategies that arise that will enable situation improvement to develop?

This domain of inquiry epitomizes the need for soft methods for inquiry, primarily because the purposes of groups are dependent on the interaction between the worldviews of its membership (whether or not a collective one exists) and the environments that the groups and their membership interact with. This demands subjective perspectives to develop. This domain of inquiry embraces uncertainty, requires work to find options for later resolution, does not permit optimisation but rather demands the search for alternative intervention strategies acceptable on separate dimensions, without trade-offs. Data inputs may be difficult to identify and collect so that novel, sometimes indirect and imaginative data collection approaches may be necessary. As such, reduced data demands are often required that may call on improved integration between hard and soft data with social judgments.

The demand for simplicity out of complexity can only be created through the development of emergence (Cohen \& Stewart, 1994). This appears to be a sort of inverse form of embedded recursion (Beer, 1975), but rather than seeing one situation embedded in another more detailed one, simple conceptualisations arises that entail the more complex detailed conceptualizations.

Not all paradigms can embrace complexity, and to assess the success of different paradigms to do so, one needs a classification system. There appears to be only one approach to classification that does this. Developed by Maruyama $(1965,1972)$, three universes have been identified that can be used to classify paradigms and methods in terms of the complex qualities of the information that they generate. These universes are referred to as, classificational, relational and relevantial, and they each have distinct natures:

1. The classificational universe is static, consists of substances classifiable into mutually exclusive categories, and is organised into a hierarchical structure of superdivisions and subdivisions (lonesco, 1989). Members of the universe are substances (material, spiritual, etc.) that are usually discrete and mutually exclusive, which can be classified into categories that can be combined or divided in a way that leads from the general to the specific, and invites ranking (Meyer, 2003). A schema in this universe generates classificational information, the purpose of which is to specify categories as narrowly as possible. Stein (2007) sees that it is also object-oriented, and Judge (2006) suggests that it operates through complex paired connections that are seen through objective epistemology. FFM provides an illustration of a schema that belongs to this universe. It arises from the five factors or dimensions of personality that were discovered through empirical research (Goldberg, 1993); a descriptive schema of personality that has not yet 
reached the status of a theory, it is supported through inadequate post-hoc propositions that neither explains personality nor operates statistically in ways that satisfy some critics $^{6}$. Research indicates that there are some important relationships between its personality factors and job performance, but even so there is a need to find hard evidence that any such approaches have any real validity (McKenna et al., 2002). Another example is Eysenk's (1957) factor analysis study of political temperament. Also, the MBTI schema that identifies a number of personality states may also belong to this universe, when the cognitive dynamics as envisaged by Jung are not made a part of its narrative.

2. The relational universe is event-oriented (Ionesco, 1989), being concerned with events and their interconnections rather than substances (Huchingson, 2001), with relational linkages and effects that are of importance (Stein, 2007). Since it is event and occurrence orientated, it drives the basic question of how do they relate to others (Meyers, 2003). It also maintains complex paired connections that adhere to a subjective epistemology (Judge, 2006). Jungian personality temperament theory may be seen as having an implicit relational nature. Mindscape theory (Maruyama, 1988) provides another example of this.

3. The relevantial universe for Maruyama (1965) is existential and dynamic in nature. It is socially connected in that it concerns individuals with shared needs and desires, and consists of individuals' concern, about themselves, about others, about situations, relations, and about existence (Meyers, 2003). It is also interpretation-oriented, maintaining a meta-view of phenomena and able to identify redundancies and variety for a system in which there are self-organization and adaptive capabilities (Stein, 2007). Here, patterns of change are represented as well as how adaptation to them can occur. Cognitively complex, it provides for both subjective and objective epistemological perspectives (Judge, 2006), where the latter presumably result from a normative consolidation of subjective perspectives. An illustration of the use of this classification approach has been used in personality theory that arises from, who sees personality is a living system that is self-organizing, self-maintaining, self-transcending, and selfrenewing. Bandura's sociocognitive self theory is also part of this universe because of its existential nature.

\subsection{The SOR Framework of Sociohistory}

Yolles et al. (2008) have created a framework called Sociohistory, housed in a relevantial Universe, that is capable of exploring sociocultural phenomena with the intention of taking measures in order to create expectations for future dynamics. It is essentially a skeleton approach that embraces SOR attributes. It is said to be skeletal because while it can be used to explore sociocultural problem situations, it has a potential to collect data and use this as inputs to evaluate the problem situations that it sees, and hence improve them through identifiable intervention strategies that have not yet been manifested. Its intended scope is limited to predicting either (i) long-term, large-scale or (ii) short-term, small-scale sociocultural events. The theory that develops, called sociohistory, links three independent but relatable approaches: part of Sorokin's epistemological theory of sociocultural dynamics, Frieden's epistemological theory of Extreme Physical Information (EPI), and Yolles's Social Viable Systems (SVS) Theory. The latter two approaches are both meta-frameworks in their own right, that have been brought together to create the sociocultural framework that has developed. The context for this has been created by Sorokin's theory. If the framework that Yolles et al. produced were well developed, it could seek data inputs through EPI, the results 
of which explain how, for instance, sociocultural processes link into political processes. One of the intentions for this framework was to use it to explore the rise of Islamic terrorism, and seek resolutions to the embedded conflict.

The theory that develops helps explain how opposing, cultural enantiomers ${ }^{7}$ (or yin-yang forces) represented by, for instance, the polar mindsets represented in Islamic fundamentalism and Global Enterprise) can result in violent conflict, or in either viable or non-viable social communities. From EPI, two forms of informations arise (I and J) that come from each of the cultural conditions, and which are regarded, respectively, as sensate and ideational enantiomers.

The theoretical framework for this work has been developed within the meta-framework of Knowledge Cybernetics. Cybernetics is concerned with the control and communication features of coherently controlled (systemic) structures and their regulation that are essential to all social (and other) contexts. It is in particular concerned with "circular causality", for instance by the action of a system in an environment that causes change. That change is manifested in the system through feedback (often in the form of information), can in turn affect the way it behaves. The feedback systems adopted in Knowledge Cybernetics arise originally from Schwarz (1997), expressed here in terms of Social Viable Systems theory, and are constituted within a metamodel of cybernetics processes of autogenesis and autopoiesis. Knowledge cybernetics is metaphorical in that it: explores knowledge formation and its relationship to information; provides a critical view of individual and social knowledge, and their processes of communication and associated meanings; and seeks to create an understanding of the relationship between people and their social communities for the improvement of social collective viability, and an appreciation of the role of knowledge in this. In a coherent autonomous human activity system knowledge occurs in structured patterns. This provides the structure that enables the system to recognise its existence, maintain itself, and change, and its manifestations constitute systemic content. While the notion of system (attributed to Bertalanffy, 1951 through his notion of the "general system") is used to explain behavioural phenomena, its cybernetic exploration derives from the work of Rosenblueth, Wiener \& Bigelow (1943) who were interested in its teleogical properties that relate to its identity, degree of autonomy and coherence. The form that the SVS metamodel has taken is defined analytically by its ontology, while its content is epistemological. This content derives from a variety of works that include contributions from Beer's cybernetic approach, Habermas's (1971) Knowledge Constitutive Interests, and Marshall's (1975) knowledge schema that links with the ideas on generic forms of knowledge by Schutz \& Luckmann (1974). In developing SVS as a social metamodel, Knowledge Cybernetics has taken into consideration communications processes. In doing this it has taken heed of the ideas of Beer (1979), ideas on lifeworld by Schutz \& Luckmann (1974), by Habermas (1987) in his theory of Communicative Action, with some incidental reference to Luhmann's (1986) social communication. Overall, the SVS metamodel is intended as a way of creating social geometries that can explore and explain complex situations.

Following Yolles (2006), the sociocultural dynamics framework that has been developed has a yin-yang cultural orientation may be thought of as an individual and collective disembodied mental construct that operates as a social force influencing patterns of thought and behaviour. It may be thought of as an autonomous dispersed ${ }^{8}$ social agent that has the potential to operate as a viable system. It is disembodied because it is not normally possible to associate it with a single named structured social organization that constitutes that construct, even though there may be individual organizations with a given orientation that constitute it. This 
is because it is constituted as a dispersed collective agent, having the capability of spontaneously establishing local social organizations of that particular cultural orientation, some of which may rise to bid for social power and the control of the social community. As such the dispersed agent is composed of a plurality of individuals, who may be interconnected by communication that is either indirect (e.g., books) or direct (e.g., interactive). It has an existential domain where beliefs (including beliefs about behavioural norms) and values exist. Behavioural norms are usually more or less adhered to by members of a cultural orientation and due to a shared history, and from this we can conceive of an implicit social structure that limits the individual's potential for behaviour. It may be expressed, for instance, as a moral code that may or may not be enforced by law. Orientational beliefs can also limit the ideate content of the noumenal domain, this ideate being composed of images or systems or coherent patterns of thought (that may include its ideology, notions of morality, or forms of rationality) that may be maintained by constructed information.

The dispersed agent therefore has at least three interconnected ontological domains. It is autopoietic because it is able to self-produce phenomenally its own components (like patterns of communications or behaviour) according to its own orientational principles (autogenesis) through a distributed network of processes. In effect this network of processes is likely to be able to phenomenally manifest the dispersed agent's own ideate. The network may involve inherent political or operative processes that may function at a personal level, and may become associated with ritual.

The orientational principles of governance (that derive from principles that are embedded in cultural knowledge, and that inform ideology and morality as well as behavioural conduct), are likely to be implicit rather than explicit, and to which the membership of each dispersed agent more or less adheres. This is because the principles emanate from knowledge that is a normative part of the orientation. Distinct ideational and sensate orientations maintain different knowledge that has semantic value only to the enantiomer. The likelihood is that the membership of a given dispersed agent will be unable to recognize the base knowledge that defines its opposite enantiomer in the yin-yang coupling. For this very reason the principles that we have referred to are likely to be different in sensate and ideational cultural orientations.

The distinction between ideational and sensate dispersed agents can be formulated as follows. Ideational dispersed agents have a cultural orientation with values that are grounded in the ideate that exists in the noumenal domain, while sensate dispersed agents are grounded phenomenally through observables that are seen to exist in the phenomenal domain. Thus, sensate and ideational concepts derive from different ontological domains, and since we are referring to value systems, these constitute a fractal of the existential domain. This difference is illustrated in Figure 3 using a recursion of SVS, embedded in the existential domain value system.

The nature of sensate orientation is that it is concerned with survival, is connected with external relationships, and tends to be concerned with the pathologies of Doing (e.g., how can we improve the survivability of a particular organization). This is in contrast to ideational orientation that is connected with the generation of ideas independent of immediate needs, to internal condition, and is often concerned with the pathologies of Being (e.g., how can we improve the likelihood of achieving enlightenment or nirvana ${ }^{9}$ ) as they are expressed through the figurative noumenon.

We have said that the cultural agents with yin-yang orientations have social behaviour and operate in a phenomenal world as a dispersed collective from which a distribution of social 
collectives may arise. We can explain the formation of such a social collective. Essentially we can think of a dispersed collective as maintaining a global cultural potential within which a set of local cultural singular identities can be manifested. Where a singular identity has duration, it has the capacity to spontaneously develop a behavioural system. When this occurs together with consciousness, the cultural singular identity has the capacity to both create a figurative noumenon, and to establish a concrete metasystem through which local primary knowledge can be created. The global cultural potential that has a capacity to manifest local social collectives can more generally be referred to as a dispersed system.

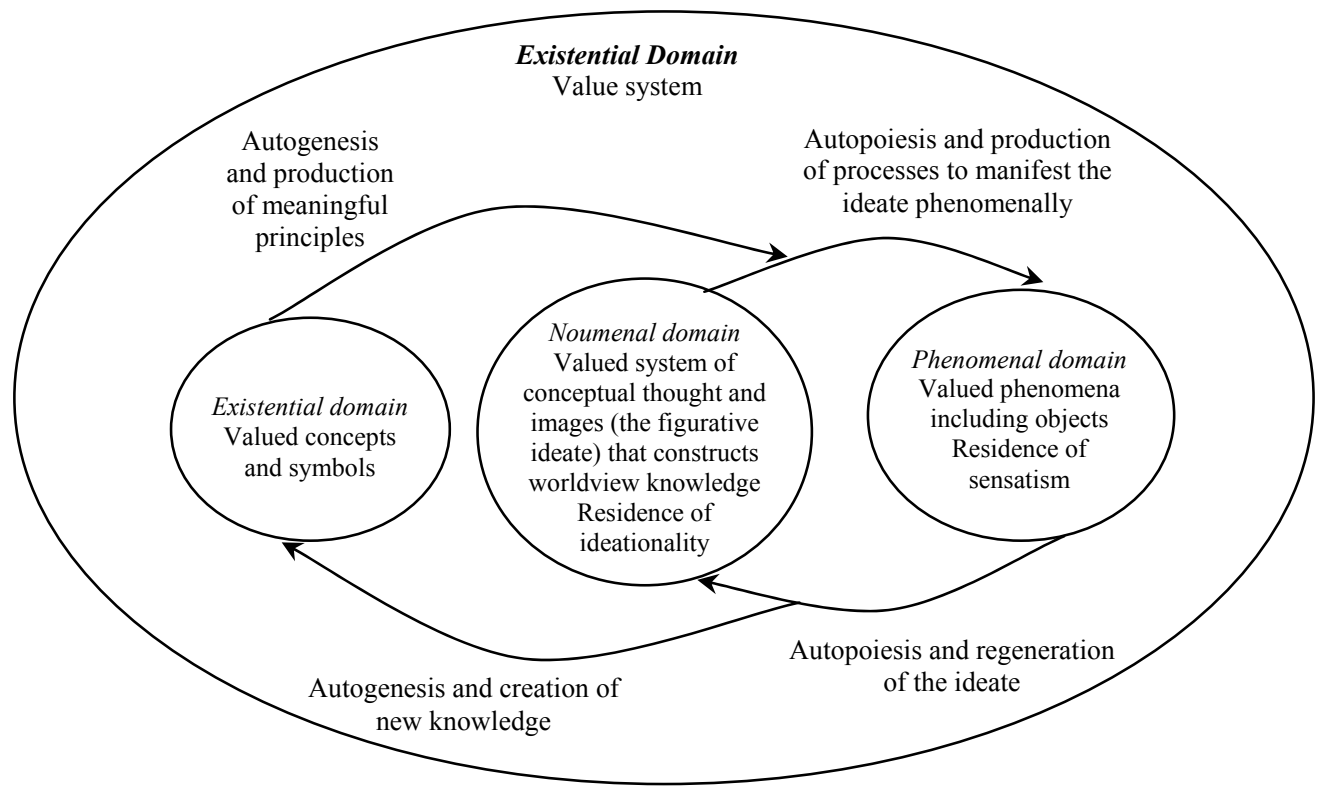

Figure 3 - Basis that Distinguishes Ideational and Sensate Values.

When the dispersed enantiomer agents develop phenomenal manifestations and interact, they can be represented as in Figure 4. Here, it is possible for information from the phenomenal world to be constructively acquired by creative observers with which a figurative noumenon can be supported and maintained. Since we are dealing with sensate and ideational dispersed agents, two classes of information consequently arise that we shall represent by $I$ and $J$, and these are housed in the noumenal domain (Figure 4). Information $I$ represents the acquired information by sensate culture, and information $J$ the theoretical basis for the society. The information natures of both $I$ and $J$ mean that they are part of the noumenal domain.

Following Frieden (1998) and Yolles \& Frieden (2005), we are aware that the informations $I$ and $J$ relate to real effects, since all real things are "capable of observation" by at least someone. This still rules out as 'real' the mathematical statements that describe effects. These are statements of the theoretical structure of the observed effect, and these statements trace from the ideational or 'source' laws. This is in fact why informations $I$ and $J$ are relatable. $I$ generates a phenomenal epistemological view of the complexity of the true source structure that $J$ is intended to describe noumenally. Acquiring the observed information $I$ allows the source to be learned or estimated. In other words both $I$ and $J$ 
describe the same thing, the only difference being that $J$ is a figurative noumenon representation of its idealized form, while $I$ generally describes it phenomenally, through locally bounded views.

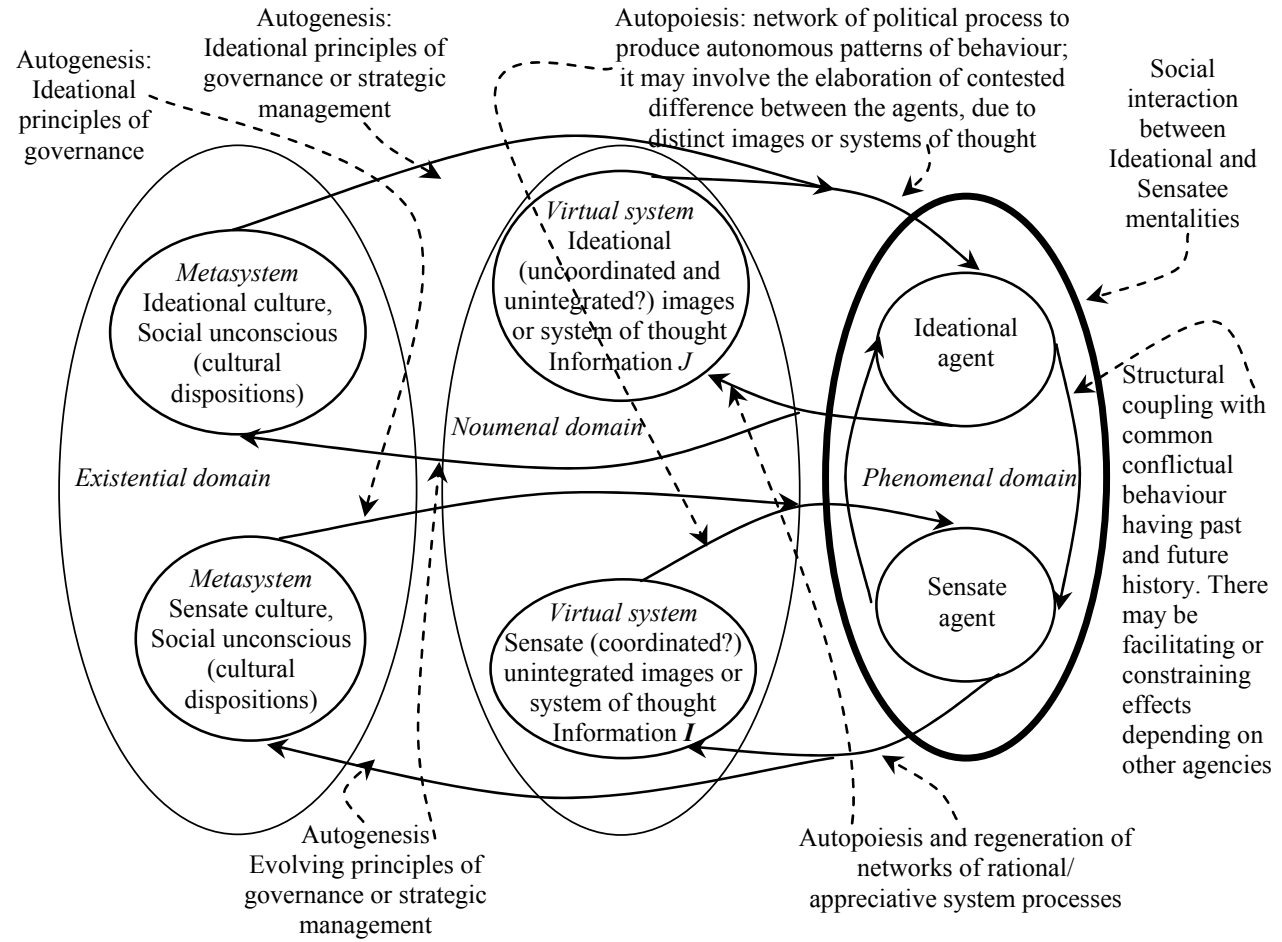

Figure 4 - Interaction between distinct Ideational and Sensate mentalities and their Social Impacts. The derivation of this type of figure can be found in Yolles (2006).

The measures of information $I$ and $J$ relate to sensate and ideational cultural orientation, and constitute part of a single noumenal domain, necessarily so since according to SVS theory it is only here that information can reside for the social agent. Sensatism and ideationality cannot exist one without the other. These informations are universal measures of structure and order (or the lack thereof). Ideationality only includes all theoretical or ideational aspects. It does not include sensate. Sensate arises out of it, and as an expression of it.

There is therefore a relationship between ideationality and sensatism. Ideational cultural orientation is everything that defines ideal rules of being and activity for human kind. As such there are at least two ways of interpreting this assignment. As the social collective through its cultural orientation attempts to carry through these rules, it can only do so inconsummately, and the attempted carry through is called sensate activity. Equivalently, but seen from a different perspective, sensate cultural orientation represents an inconsummate attempt to carry through ideational rules.

These orientations are, however, disembodied. They are manifested through agents of cultural orientation as illustrated in Figure 4. These manifestations are expressed as a 
phenomenal social conflict process. We take it that $J$ represents the total level of structural information in the given system, with complete accuracy. This structural information exists as ideals and laws. People act in response to culturally transmitted ideas that are embedded in symbolic representations of structural information.

Ideational and sensate cultural orientations are enantiodromic distinctions, and differentiate between what people might aspire to (ideationality) and what they actually achieve (sensatism). There is in a sense a "conflict" between the two, in that they don't completely agree. Also, perhaps more to the point, people purposely don't carry through the ideational most of the time. This purposefulness might indicate the "conflict" that they seek. This is also sometimes termed "pragmatic" activity, as in a "white lie" which we "shouldn't" do (ideational) but do anyhow, on the grounds of a "better good" for everyone concerned. A white lie is an example of a small difference between the ideational and the sensate. When the difference becomes large enough, according to some interpretations this would indicate a kind of conflict called a "sin."

The natures of the senate and ideational orientations can vary absolutely or relatively. Let us consider the absolute first. The enantiomer yin-yang orientations change in their levels of complexity, or at least degrees of order, and the interest is to identify the nature of that order because this has an impact on the way the society behaves. Since $I$ and $J$ are measures of these orientations, we wish to evaluate their change relative only to themselves (we refer to this as absolute change). A low value of $I$ implies a simple sensate society, and a high value of $J$ implies a complex ideational society. We shall refer to these conditions as primitive, since sensate primitiveness suggests a low technological level and hence an inability to cope well with complex change; and ideational primitiveness suggests a society that is so bound up by complex ritual that it dominates peoples lives, either by its conspicuous absence (in atheists or agnostics) or its conspicuous presence (in priests or zealots). Also, with $I<<J$ the high order/complexity of the ideational rules are not being practiced on the sensate level.

These arguments, those given below, and indeed the entire theory that Yolles et al. have developed, are as yet largely untested. At this point the results or interpretations cannot therefore be considered to be decisive. The aim is to initiate the theory that can develop into an OR method, with the hope that it is reasonable and self-consistent, and will stimulate further inquiry into the subject along these lines.

Second, consider the other extreme when $\mathrm{I}<<\mathrm{J}$. Where the received information I is very low, describing a noisy, chaotic system, sensory experience randomly and widely diverges from the social norms of the ideational aspect. This might be manifest in a breakdown of morality, a high crime rate, etc. The society cannot function in accordance with its own rules. Consequently it will be too impractical to exist. Hence, when a society has a dominant sensate orientation, it will run out of ideas and likely will be unable to viably respond to new challenges and may even have difficulty conceptualizing them. At the other extreme, an ideationally dominated society will become more and more impractical, and likely will centre on ritual rather than be responsive to internal or environmental pressures. In either case the society will start to stagnate and will become 'structurally critical', increasingly unable to cope with problems and crises that it will face (e.g. famine, external war, inflation). In this increasing critical state even small perturbations in the system may affect it in a major way.

An example of the shifting relative values of $I$ and $J$ can be suggested through conjecture. In early Greek society the slave and merchant classes took care of the culture's operational and 
external needs, while the ruling class pursued its ideational needs. The conjecture is that as more slaves were acquired the ruling class had more time for building up its ideology. Thus, the ideational level $J$ of information went up. But also, since the slaves added degrees of freedom to the system, this increased the sensate level of Fisher information. Thus, both $J$ and $I$ increased in value. Taking an autopoietic view, ambient political or operative processes were consequently dominated by ideational orientation and benefited those pursuing an ideational future.

In summary, ideational or sensate dominated cultural orientation will fail to meet the needs of its members. This will lead to a loss of confidence by society in the direction that cultural orientation takes it. The debate and conflict will re-open, other mentalities will reassert themselves, and the chaotic state will return. This period maybe described as chaotic in the sense that it appears to have no direction, and conflict has a greater likelihood of becoming phenomenally manifested. Since the chaos results from the inabilities of one orientation to meet that crisis, one would expect the alternative orientation to gain adherence and ascendancy within that chaotic period. This may not happen, and an existing dominant cultural orientation may simply re-assert itself, but in doing so, society will still remain structurally critical. Inevitably, it will change its orientation or the society.

The political dimension of dynamic sociocultural processes illustrated here is important. Political debate by members of a society constitutes an innate conflict on the value of these mentalities in its social and cultural development. The resultant is a pulling of society in many directions, which may becomes chaotic and unstable.

One of the outcomes of the innate conflict (and therefore the political processes that accompany them) is that it can become resolved into the emergence of a balanced cultural orientation as the agents establish an alliance and a new cultural agent is formed. By this we are referring to Sorokin's integral notion, but broaden it so that it can develop a variable cultural orientation determined not only by the state of the enantiomers, but also the mix that results between them. This notion is consistent with the development joint alliances in smallscale societies (Yolles, 2001; Iles \& Yolles, 2002; Iles \& Yolles, 2003a), and there is no apparent reason to argue that it cannot also be valid for large-scale societies. The emergence of such a balance (represented as $\underline{K}$ ) occurs initially through political or operative processes that enables the cultural agents to co-exist, and which may become stable if it develops its own virtual system and metasystem. It does not assume that the individual cultural orientation enantiomers disappear, but rather that as a yin-yang couple they each maintain their existence and interact with the emergent balanced form, as illustrated in Figure 5.

It is supposed here that a balance is always maintained between information $I$ (measuring "survival ability") and information $J$ (measuring "degree of structure" relating to the internal conditions of a socioculture). This continuous maintenance of balance directly means that the theory is one of general inhomeostatic non-equilibrium. Homeostasis, by comparison, is usually attained only after the passage of time due to the dynamic nature of the equilibrium. 


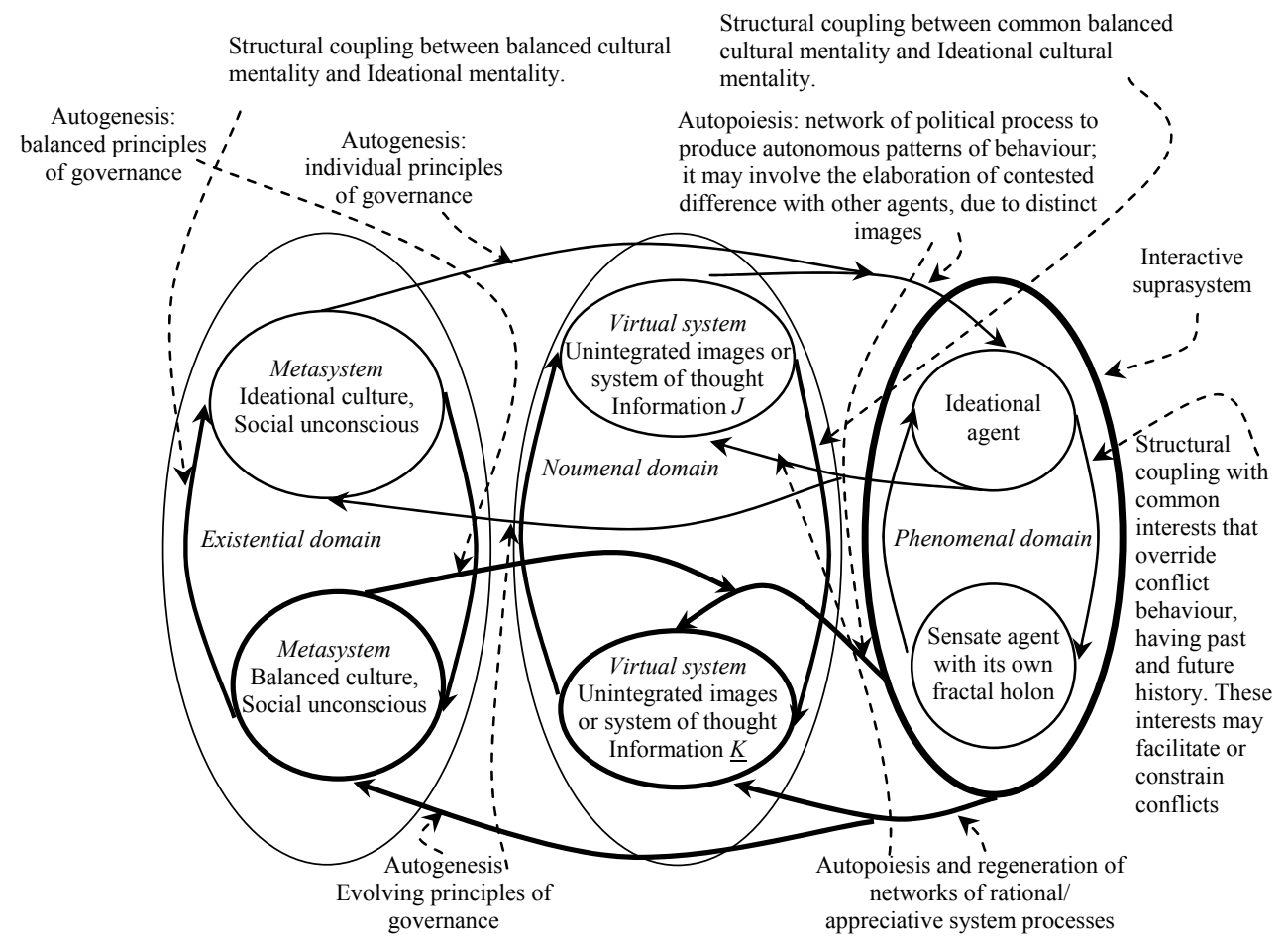

Figure 5 - Relationship between Ideational and/or Sensate Cultural Orientations and an Emergent Hegelian "Alliance" or Balanced Culture.

\subsection{Understanding the Measurables}

In this section we shall not enter into the mathematical details (it would be more appropriate to refer to the fuller explanation provided in Yolles et al. (1998) for this). Rather, we shall simply offer some core principles that enable intervention strategies to be identified and evaluated. Such intervention strategies are ultimately a function of the measurable probability values that develop.

The EPI meta-framework provides a means for creating measurable from the informations $I$ and $J$. EPI adopts two core principles, the first of which is:

$$
I=\kappa J, \quad 0 \leq \kappa \leq 1 .
$$

This shows that the constant $\kappa$ is a measure of the efficiency with which the information is transferred from the effect to the observer. The efficiency parameter is always between 0 $(0 \%$ efficiency) and 1 ( $100 \%$ efficiency). Its value depends upon the quality of the detectors and the particular effect that is under observation. For example, when observing quantum ${ }^{10}$ effects if the detectors are perfect then $\kappa=1$. No information is lost. Or, by comparison, classical effects such as gravitation or electromagnetism are presumed to arise out of imperfect observation due to detectors that lose half the information, with $\kappa=1 / 2$. The data are then too coarsely spaced in space-time to sense the much finer, quantum fluctuations. In our sociocultural application the value of $\kappa$ will vary from one sociocultural system to another. 
Eq. (1) states that the acquired information $I$ has the "potential" to equal the value of $J$ at most. In applications where $I=J$, all the information necessary to describe the noumenon is now available in the observations. A result is that the noumenon, and not merely the phenomenon, can be known. That is, the probability law $p(\mathbf{y} \mid a)$ that is the output of EPI now describes the noumenon as well as the phenomenon. This happens, for example, for measurements that are on the level as indicated above.

The "physical information" $K$ is defined to be the change $\Delta I$ in the information from source to data collector(s),

$$
K=I-J
$$

$K$ is always zero or negative, indicating that it is generally an information loss. This means that the state of disorder of the system increases. This is another way of saying that $K$ is at some extreme value,

$$
K=I-J=\text { extremum }
$$

This is the second principle of extreme physical information (EPI). The extreme value is attained through variation of the likelihood law $p(\mathbf{y} \mid a)$ and subject to the relation (6) connecting $I$ and $J$. In classical problems, such as this one, the extremum is a minimum in particular. Also, the ideal parameter $a$ is here the unknown time $t$ at which a system of populations is randomly sampled, giving rise to some observed population type $n$. Hence the generic datum $\mathbf{y}$ is here $n$, and the likelihood function $p(\mathbf{y} \mid a)$ is a probability law $P(n \mid t)$ on $n$ if $t$, which is conventionally denoted as $p_{n}(t)$. This represents the "growth law" for population component $n$. The totality of such growth laws $p_{n}(t), n=1, \ldots, N$ describes the overall system, which can be a sociocultural one. Hence our aim will be to compute these laws.

Note that since the time $t$ is general, we are not limited in this approach to seeking equilibrium states of these probability laws. Equilibrium states are defined at the particular limiting time $t \rightarrow \infty$. Instead, the EPI solutions will be expressed as functions $p_{n}(t)$ of a general time value. Thus, they represent in general non-equilibrium solutions. Such functions of the time are also termed "dynamical" solutions, as in problems of Newtonian mechanics. EPI is eminently suited to finding such non-equilibrium solutions, having already done so in problems of statistical mechanics (Flego et al., 2003; Frieden, 1998; Frieden et al., 1999; Frieden et al., 2002), econophysics (Hawkins \& Frieden, 2003), and cancer growth (Gatenby \& Frieden, 2002).

The application of EPI principles results in a number of additional sociocultural principles that create constraints for sociocultural dynamics. Thus for instance:

A society in which $\kappa$ is close to zero or to unity is dominated either by sensate or ideational disposition. With a sensate disposition, the society will run out of ideas, and likely will be unable to viably respond to new challenges and may even have difficulty conceptualising them. At the other extreme, an ideationally dominated society will become more and more impractical, and likely will center on ritual rather than be responsive to internal or environmental pressures.

In either case the society will start to stagnate and will become 'structurally critical', increasingly unable to cope with problems and crises that it will face (e.g. famine, external war, inflation). In this increasing critical state even small perturbations in the system may affect it in a major way. 
EPI provides a physical description of a system. It is assumed that the society is adequately described by the frequency of occurrence values $\mathrm{p}_{\mathrm{n}}(\mathrm{t})$ of its major population components $\mathrm{n}=1, \ldots, \mathrm{N}$. Components $\mathrm{n}$ include the various peoples of the society, labelled in some arbitrary way, and also its capital resources. For purposes of a practical analysis, a minimal number $\mathrm{N}$ of such resources is chosen, specifically, those resources that have a significant effect upon the populations. Examples are arable land, retrievable oil, forests, and gold in reserve. With the components $n$ so defined, an occurrence value $p_{n}(t)$ is defined to be the relative amount of substance of type $\mathrm{n}$ that is present in the society at the time $t$. This can be quantified as the number of (say) cubic meters of type $\mathrm{n}$ divided by the total number of cubic meters over all categories $n=1, \ldots, N$. The $\mathrm{p}_{\mathrm{n}}$ are then also probabilities, in the sense that if a cubic meter of the society (be it of a person, piece of land, sample of oil, etc.) is randomly sampled from it, it will of type $\mathrm{n}$ with probability $p_{\mathrm{n}}$ (the "law of large numbers": see Frieden, 2001).

The OR problem involves establishing the occurrences $p_{\mathrm{n}}(t)$ of the various population components, their internal spatial structures are ignored. However, the time-dependences of the $p_{n}(t)$ of course result from changes in position $(x, y)$ of the population members, and these changes in position depend upon their mass values. This is qualitatively because mass is a metaphor for resistance to such change, and hence can be regarded as a type of "inertia." Hence a cubic meter of substance of general type $n$ is assumed to have a known mass value $m_{\mathrm{n}}$. This ignores individual variations in mass among the members of type $n$. In a sense, each is regarded as a featureless "particle."

Another physical concept is the "potential function", a function $V(x, y, t)$ of position and time. This defines the cause of the motion or dynamics of a given system. For example, this source might be a spring, in which case the potential is specified as of the form $V \propto x^{2}$. An illustration within a sociocultural context would be that knowledge creates a potential that can be related to some measure of social distance. In any given problem the potential must be known, and it usually has a simple form.

\section{Conclusion}

This paper supports the proposition that paradigms are living social systems with a life cycle constituted by gestation, birth, growth, duration, maturity and death. The paradigm is a metaphor for the dynamic self-organising social group that creates, carries, maintains and develops it. Paradigms grow through their commodities, but successful growth bounds them within epistemological limits.

The idea that OR paradigms have shifted from traditional hard approaches that are associated with simple situations, to soft ones that can be more associated with complexity, is explained and illustrated through the use of Viable Systems cybernetic theory. An illustration of a soft theoretical framework that has recently developed is provided, that satisfies a number of criteria that are required within a SOR approach. Its purpose is to describe, explore and evaluate sociocultural problem situations, but at present it is skeletal because its future potential to fully evaluate sociocultural problem situations, and develop appropriate intervention strategies to improve them, is limited. The need to develop this attribute is to develop further the data acquisition techniques, which EPI can then process, thereby enabling Knowledge Cybernetics to interpret the outputs and convert them into intervention strategies. 


\section{References}

(1) Bandura, A. (1986). Social foundations of thought and action: A social cognitive theory. Prentice-Hall, Englewood Cliffs, NJ.

(2) Beer, S. (1975). Platform for Change. Wiley, Chichester.

(3) Beer, S. (1979). The Heart of the Enterprise. Wiley, Chichester.

(4) Beer, S. (1980). Preface to the Maturana, H. and Varela, F.J., Autopoiesis: The Organization of the Living contained in Preface in Maturana, H., Varela, F.J., Autopoiesis: The Organization of the Living [edited by R.S. Cohen and M.W. Wartofsky], p.63-67, Boston Studies in the Philosophy of Science series vol. 40, D. Reidel Publishing Co., Dordecht. Also see <www.cogsci.ed.ac.uk/ jwjhix/Beer.html>, accessed 2003.

(5) Beer, S. (1985). Diagnosing the System. Wiley, Chichester.

(6) Bertalanffy, L.V. (1951). General Systems Theory: a new approach to the unity of science. Human Biology, 23(Dec.), 302-361.

(7) Casti, J.L. (1989). Paradigms Lost. Abacus, London.

(8) Cohen, J. \& Stewart, I. (1994). The Collapse of Chaos: discovering simplicity in a complex world. Viking, London.

(9) Eysenk, H.J. (1957). Sense and Nonsense in Psychology. Penguin Books Ltd, Harmonsworth, Middlesex, UK.

(10) Fischer, K. (1992). The Social and Cognitive Dynamics of Paradigmatic Change: A Scientometric Approach Science in Context. Cambridge University Press, 5, 51-96.

(11) Frieden, B.R. (1998). Physics from Fisher Information: A Unification. Cambridge University Press, Cambridge. Also see <www.optics.arizona.edu/Frieden/Fisher information.htm>, accessed 2002. There is also a 2004, $2^{\text {nd }}$ ed., Science from Fisher Information. Cambridge University Press, U.K.

(12) Funtowicz, S.O. \& Ravetz, R. (1993). Science for the post-normal age. Futures, 739-755.

(13) Goldberg, L.R. (1990). An alternative 'description of personality': the big-five factor structure. Journal of Personality and Social Psychology, 59, 1216-29.

(14) Goldberg, L.R. (1993). The structure of phenotypic personality traits. American Psychologist, 48, 26-34.

(15) Habermas, J. (1971). Knowledge and Human Interests. Beacon Press, Boston.

(16) Habermas, J. (1987). The Theory of Communicative Action. Vol. 2, Polity Press, Cambridge, UK.

(17) Hatch, M.J. \& Cunliffe, A.L. (2006). Organization Theory. Oxford University Press.

(18) Hessels, L.K. \& van Lente, H. (2008). Re-thinking new knowledge production: A literature review and a research agenda. Research Policy, 37, 740-760.

(19) Hoffman, B. (1947). The Strange Story of the Quantum. Penguin Books, Middlesex, UK.

(20) Huchingson, J.E. (2001). Pandemonium Tremendum: Chaos and Mystery in the Life of God. The Pilgrim Press, Cleveland.

(21) Iles, P. \& Yolles, M. (2002). International joint ventures, HRM and viable knowledge migration. International Journal of Human Resource Management, 13(4), 624-641. 
(22) Iles, P. \& Yolles, M. (2003). International HRD alliances in viable knowledge migration and development: The Czech Academic Link Project. Human Resource Development International, 6(3), 301-324.

(23) Judge A. (2006). Towards an Astrophysics of the Knowledge Universe: from Astronautics to Noonautics. <http://www.laetusinpraesens.org/docs00s/astruni.php>, accessed August 2008.

(24) Kincheloe, J.L. \& Horn, R.A. (2008). The Praeger Handbook of Education and Psychology. Vol. 1, Greenwood Publishing Group, accessible through $<$ http://books.google.co.uk>.

(25) Kuhn, S.T. (1970). The Structure of Scientific Revolutions. $2^{\text {nd }}$ edition, University of Chicago Press, Chicago, The first edition was published in 1962.

(26) lonesco, M. (1989). Regional Cooperation for Research Collections. Collection Building, 9(2), 7-11.

(27) Lucas, C. (2002). Quantifying Complexity Theory. <www.calresco.org/lucas/ quantify.htm>, accessed May 2003.

(28) Luhmann, N. (1982). The Differentiation of Society. Columbia University Press, New York.

(29) Marshall, S.P. (1995). Schemes in Problem Solving. Cambridge University Press, Cambridge, UK.

(30) Maruyama, M. (1965). Metaorganization of Information: Information in a Classificational Universe, Relational Universe, and Relevantial Universe. Cybernetica, 8(4), 224-236.

(31) Maruyama, M. (1972). Non-Classificational Information and Non-Informational Communication. Dialectica, 26(1), March, 51.

(32) Midgley, G. (1992). Power and Language of Cooperation: a Critical Systems Perspective. Sistemica'92. Paper given at the Primera Conferencia International de Trabajo del Instituto Andino de Systemas (IAS), Lima-Peru.

(33) McKenna, M.K.; Shelton, C.D. \& Darling, J.R. (2002). The impact of behavioral style assessment on organizational effectiveness: a call for action. Leadership \& Organization Development Journal, 23(6), 314-322.

(34) Meyer, R. (2003). Systems, Sustainability and Design. $6^{\text {th }}$ Asian Design International Conference, 14-18 October, Tsukuba International Congress Centre, University of Tsukuba, Japan, accessible at <www.idemployee.id.tue.nl/g.w.m.rauterberg/ conferences/CD_doNotOpen/ADC/final_paper/348.pdf $>$.

(35) Nicolis, G. \& Prigogine, I. (1989). Exploring Complexity: An Introduction. W.H. Feeman and Co., New York.

(36) Oakley, T. (2004). Elements of Attention: A New Approach to Meaning Construction in the Human Sciences. <http://www.mind-consciousness-language.com/articles\%20 oakley1.htm>, accessed January 2009.

(37) Prigogine, I. \& Stengers, I. (1984). Order Out of Chaos: Man's New Dialogue with Nature. Flamingo, London.

(38) Rauterberg, G.W.M. (2000). How to characterize a research line for user-system interaction. IPO Annual Progress Report, 35, 66.

(39) Ravetz, J.R. (1999). What is Post-Normal Science. Futures, 31(7), 647-653. 
(40) Rosenblueth, A.; Wierner, N. \& Bigelow, J. (1943). Behaviour, Purpose and Teology. Philosophy of Science, 10(1), 18-24.

(41) Schutz, A. \& Luckmann, T. (1974). The Structures of the Lifeworld. Heinamann, London.

(42) Schwarz, E. (1997). Towards a Holistic Cybernetics: From Science through Epistemology to Being. Cybernetics and Human Knowing, 4(1), 17-50.

(43) Schwarz, E. (2001). Anticipating Systems: an Application to the Possible Futures of Contemporary Society. Invited paper at CAYS'2001, Fifth International Conference on Computing Anticipatory Systems, Liege, Belgium, August 13-18.

(44) Schwarz, E. (2003). Is Consciousness Reality or Illusion? A Non-Dualist Interpretation of Consciousness. Computing Anticipatory Systems: CASYS'03 - Sixth International Conference, Liege (Belgium), August 11-16.

(45) Stein, V. (2007). Human Capital Management: The German Way. German Journal of Human Resource Research, 21(3), 295-321. Also see <http://www2.uni-siegen.de/ $\sim \mathrm{fb} 05 \mathrm{pmg} /$ content/veroeffentlichung/ZfP_03_2007_Stein_HCM.pd $>$.

(46) Weizsäcker, E.U.V.; Lovins, A.B. \& Lovins, L.H. (1997). Factor Four: Doubling Wealth, Halving Resource Use - The New Report to the Club of Rome. Earthscan Publications, London.

(47) Wilson, G.B. (1984). Organizational Jung. New Catholic World, March/April, 227(1358). <www.gbwilson.homestead.com/files/Organizational_Jung.htm>, accessed December 2004.

(48) Yolles, M.I. (1998). Changing Paradigms in Operational Research. Cybernetics and Systems, 29(2), 91-112. See <http://ssrn.com/author=1211894>.

(49) Yolles, M.I. (1999). Management Systems: a viable approach. Financial Times Pitman, London.

(50) Yolles, M.I. (2001). Viable Boundary Critique. Journal of Operational Research Society, January, 51, 1-12.

(51) Yolles, M.I. (2006). Organisations as Complex Systems: an introduction to knowledge cybernetics. Information Age Publishing, Inc, Greenwich, CT, USA.

(52) Yolles, M.I. (2007). From Sociohistory to Psychohistory. Kybernetes, 36(3/4), 378-405. Invited paper for special issue on management.

(53) Yolles, M.I. (2009). Migrating Personality Theories Part 1: Creating Agentic Trait Psychology? Kybernetes, 36(6), in process.

(54) Yolles, M.I. \& Frieden, B.R. (2005). A Metahistorical Information Theory of Social Change: The Theory. Organisational Transformation and Social Change, 2(2), 103-136.

(55) Yolles, M.I.; Frieden, R. \& Kemp, G. (2008). Toward a formal theory of sociocultures: A yin-yang information-based theory of social change. Kybernetes, 37(7), 850-909. See $<$ http://ssrn.com/author $=1211894>$. 


\section{Notes}

${ }^{1}$ Two classes of value are possible: cultural and epistemic. Cultural values define the mode of practice that is open to a group who maintain a paradigm, and may be distinguished according to its sensate or ideational orientation. In contrast epistemic values are (for Kincheloe \& Horn, 2008) criteria employed to chose among competing explanations. The two tend to be tied together, and an explanation for this is unintentionally indicated by Kincheloe \& Horn, 2008, p.264): "The Questions on epistemic values rarely arise in objectivistic metatheory, since knowledge is viewed as a representation of reality and, consequently, explanations are chosen according to their truth value - that is their correspondence with the external reality they represent. The objectivist conception of knowledge and truth are thus closely linked with imbued science - with the reliance on facts to justify a given knowledge claim. Constructivism...departs from a representational conception of knowledge. Justification by means of the authority of truth is then regarded as illusion. This nonjustification position leaves constructivist metatheory facing the task of articulating an alternative set of epistemic values, taking into account that values are, by definition, subjective preferences....Two of the most pervasive sets of epistemic sets of values in constructivist metatheory, however, correspond to (a) the pragmatic value of knowledge claims (i.e., their predictive efficacy, viability and fertility) and (b) the coherence of knowledge claims (i.e., their internal and external consistency and unifying power)." (Kincheloe \& Raymond A. Horn, 2008, p.264).

${ }^{2}$ Available for download from www.harzing.com/resources.htm\#/pop.htm.

${ }^{3}$ While we shall engage with this notion again in due course, in effect we are suggesting that normal modes of science operate through equilibrium processes of inquiry. Systems that are in equilibrium are not able to deal with fundamental change. In stable situations, the creation of new approaches is difficult. Structures, rules, procedures and plans need to be changed when shocks are encountered; but this is problematic because of the norms and cultural attributes of a given system. In contrast post-normal modes involve a competitive plurality that operates in an essentially dissipative environment in the sense of Prigogine \& Stengers (1984). They thus manifest interactive processes that are non-equilibrium, inherently dynamically unstable, use energy to maintain order beyond any thresholds of instability, and their behaviour is subject to fluctuation.

${ }^{4}$ A virtual paradigm (Yolles, 1999) exists as a "candidate" paradigm that arises around a set of ideas as a formalized non-normative or semi-formalized set of shared worldviews, and it may or may not become solidified into a paradigm. It appears to be consistent with Fischer's (1992) notion of the pre-paradigm.

${ }^{5}$ Since cognitive values may be distinguished into cultural and epistemic values, a change may develop as the result of cultural and/or epistmic changes. As already explained, the two often go together. If we consider that the normal condition of a paradigm is when it has a single dominant cultural group who embrace a particular set of cultural and epistemic values, then the rise of the post-normal mode occurs with development of a contrasting cultural group which embraces contrasting cultural and epistemic values. The most general way of arguing this is to accept Sorokin's thesis which will be described in due course, and say that one group will be either sensate or ideational, and the opposite (ideational or sensate) will rise as it moves out of normal mode. In modern times the dominant group was sensate (i.e., hard science), and ideationalists have risen in opposition in order to contend with issues of perceived complexity. Two things may happen then. Either conflict will 
develop and the paradigm shifts into crisis, or an "Ideal" balance between the two will develop, when the paradigm may stay in the post-normal mode as long as the balance is maintained. The feature of post-normal modes is that work is required (since post-normal mode is far from equilibrium) to maintain the balance. If after the crisis transformation occurs so that one cultural group dominates, then the paradigm is likely to slip back into equilibrium mode, where any incremental changes it makes are reversible....i.e., "gained" ground may be lost. This dynamic does not have to start with a sensate normal mode as has happened in recent decades. The reason is that the nature of what constitutes simple and complex is relative to the perceiver (Yolles, 1999; Midgley, 1992, p153). Thus through the development of emergence (Cohen and Stewart, 1994) the complex may slip into the simple as the transformational mode of a paradigm shifts into the normal mode.

${ }^{6}$ See for instance http://en.wikipedia.org/wiki/Big_Five_personality_traits, accessed April 2008.

7 The term enantiomer (also enantiomorph that in particular relates to form or structure) means a mirror image of something, an opposite reflection. The term derives from the Greek enantios or "opposite," and is used in a number of contexts, including architecture, molecular physics, political theory, and computer system design. We use it in the sense of complementary polar opposites. The related word enantiodromia is also a key Jungian concept used in his notions about consciousness (e.g., http://www.endless-knot.us/ feature.html), and (from the OED Online) it is the process by which something becomes its opposite, and the subsequent interaction of the two: applied especially to the adoption by an individual or by a community, etc., of a set of beliefs, etc., opposite to those held at an earlier stage. For Jung the word enantiodromia represents the superabundance of any force that inevitably produces its opposite. Consequently the word enantiodromia often implies a dynamic process which is not necessarily implied by the word enantiomer. By using the simpler word enantiomer we shall not exclude the possibility of any dynamic action that may have been implied by the term enantiodromia.

${ }^{8}$ The dispersed agent, once it is conceptualised, is deemed to exist either: (a) in an ideational world because it is an essence that can be manifested in its ideate, and (b) in a sensate world if it can be identified phenomenally and measured. The nature of the dispersed agent is that it is actually an existential condition that provides a potential for the manifestation of a system. Such systems may or may not arise, depending on the complex nature of the social fabric. Where they arise, they do so from the "existential" condition that facilitates a particular "existential type" of system. When an existential type of system does arise, even temporarily, it is because a local stability has formed as a singular identity. It explains the possibilities for the spontaneous rise of particular systems. Where an existential type of system spontaneously arises, one might wish to look for an existential potential, a dispersed system.

${ }^{9}$ Any place of complete mental bliss and delight and peace.

${ }^{10}$ The quantum effects in socioculture have not yet been adequately identified, and the further qualitative examination of sociocultural dynamics is required to understand the nature of this. However, according to Yolles et al. (2008), populations can consist of either: (a) microscopic quantum "nano-life"; (b) macroscopic classical "social-life" where people exist in competing populations within organizations, or (c) any mixture of both. There is also speculation in the paper that the quantum attributes occur with classical ones as part of a living system autopoiesis, with nano-life having an origin that emerges from thought as it connects with practice. 